\title{
PEG INSERTION UNDER TIVA IN AN INFANT WITH SPINAL MUSCULAR ATROPHY TYPE I: A CASE REPORT
}

\author{
Chandrakala K. R ${ }^{1}$, Bhagya D. V², Chandrika Y. R ${ }^{3}$, Anuradha G4 ${ }^{4}$ Madhavi N5
}

\section{HOW TO CITE THIS ARTICLE:}

Chandrakala K. R, Bhagya D. V, Chandrika Y. R, Anuradha G, Madhavi N. "PEG Insertion Under Tiva in an Infant with Spinal Muscular Atrophy Type I: A Case Report". Journal of Evolution of Medical and Dental Sciences 2014; Vol. 3, Issue 29, July 21; Page: 8197-8200, DOI: 10.14260/jemds/2014/3030

\begin{abstract}
Spinal Muscular Atrophy (SMA) is a rare genetic disease characterized by progressive degeneration of spinal cord motor neurons resulting in hypotonic muscle weakness. ${ }^{1}$ Out of the four types, type I is the most severe, presenting at 0 to 6 months. This is the most challenging type for anaesthetic management due to muscular weakness, airway difficulties, hyper sensitivity to non depolarising muscle relaxants, risk of hyperkalemia and difficulty in intravenous cannulation. ${ }^{3}$ Here we present a case of SMA type I infant posted for percutaneous endoscopic gastrostomy [PEG] tube insertion under total intravenous anaesthesia [TIVA].
\end{abstract}

KEYWORDS: SMA-Spinal Muscular Atrophy, PEG-percutaneous endoscopic gastrostomy tube, TIVA Total intravenous anaesthesia.

INTRODUCTION: Spinal muscular atrophy is an incurable, severe neuromuscular disease characterized by degeneration of alpha motor neurons in the spinal cord, resulting in progressive proximal muscle weakness and paralysis. First described in the 1890s by Werdnig and Hoffmann, the genetic defect was localized to 5q11.2-q13.3 and a century later with the identification of the survival motor neuron gene (SMN) as the disease-causing gene in 1995.[1 \&7] SMA is the second most common fatal autosomal recessive disorder after cystic fibrosis with a high mortality rate in infancy and severe morbidity in childhood. ${ }^{2}$

Weakness may affect several organ systems: respiratory - due to restrictive lung disease; gastrointestinal - in terms of dysphagia and constipation; orthopedic - with progressive deformities. Overwhelmingly, the most serious complication of spinal muscular atrophy is restrictive lung disease. The severity of restrictive lung disease is generally proportional to the weakness; it therefore is most severe in infants with spinal muscular atrophy type 1 and may be progressive because of recurrent micro-atelectasis causing failure of lung development with linear growth. ${ }^{2}$

Restrictive lung disease may be further complicated by recurrent aspiration and infection. Type I SMA may also have associated bulbar weakness as well. Dysphagia and fatigue during feedings may result in failure to thrive which may exacerbate weakness, setting up a cycle of poor feeding, fatigue, and weakness resulting in more difficulty feeding. Persistence with oral feeds may result in aspiration pneumonia. Hence Percutaneous gastrostomy is indicated early before patients develop pneumonia and most patients will benefit from it.

CASE REPORT: A 10 months old malnourished infant weighing 6.8kgs with type I SMA presented for PEG insertion due to frequent episodes of upper respiratory tract infection, pneumonia and feeding difficulties with nasogastric tube. On examination infant was alert, irritable, had a weak cough. Infant also was dolicocephalic, had pectus excavatum with normal vitals of HR-90/min, Spo2-98\%, RR$25 / \mathrm{min}$, blood pressure-80/50 mm of $\mathrm{Hg}$ with good hydration. Milestones were delayed with no neck 
holding, unable to sit, spoke mono-syllables and recognized mother. There was gross hypotonia (generalized) and power of grade 2/5 in proximal and distal 1/5with absent deep tendon reflexes.

Systemic examination of respiratory system revealed bilateral coarse crepitations and conducted sounds. Investigation showed haemoglobin $-15.2 \mathrm{gm} \%$, total count $-7400 \mathrm{cells} / \mathrm{cu} \mathrm{mm}$, Platelets 2,27,000, Random blood sugar - $80 \mathrm{mg} \%$, Blood urea - $80 \mathrm{mg} / \mathrm{dl}$, S. Creatinine Phosphokinase - 36.6, Serum lactate - 34mg/dl Serum creatinine - $1.3 \mathrm{mg} / \mathrm{dl}$, CSF lactone $10.5 \mathrm{ng} / \mathrm{ml}$, Serum ammonia - 76. Chest X-ray, TMS, MRI brain were normal. Electron microscopy of muscle revealed no evidence of rod bodies or any form of inclusions.

Muscle biopsy done under local anesthesia and confirmed neurogenic atrophy. The infant was accepted under ASA IIIE risk for the proposed procedure.

On the day of surgery, premedication with oral midazlam syrup $0.5 \mathrm{ml} / \mathrm{kg}$ was given. After connecting spo2 probe, ECG leads and noninvasive blood pressure monitor, 24G intravenous cannula was secured on right foot and another on left hand without sedation/inhalation. Cannulation was difficult, as the hypotonia posed difficulty in identifying plane of cannula insertion. Ringer lactate intravenous fluid connected and given according to holliday- segar formula.

Nasogastric tube of 8 numbers was inserted. After pre oxygenation with $100 \%$ oxygen, induction was done with intravenous propofol 40mg and Fentanyl 15mg; intubation was done under spontaneous ventilation without muscle relaxants with $4.0 \mathrm{~mm}$ uncuffed oral endotracheal tube in second attempt because of high larynx and large overhanging epiglottis.

Intra-operative anaesthetic maintenance was done with oxygen: nitrous oxide and propofol infusion at $5 \mathrm{mg} / \mathrm{kg} / \mathrm{hr}$. Peri-operative vitals remained stable throughout the surgery. After 45 minutes, towards the end of procedure there was smooth recovery with spontaneous breathing efforts and baby was extubated after proper suction.

Postoperatively child was fine with normal vitals and shifted toward uneventfully.

DISCUSSION: Spinal muscular atrophy is a neuromuscular disease characterized by degeneration of alpha motor neurons in the spinal cord, resulting in progressive proximal muscle weakness and paralysis with incidence of 1:6000 to 1 in 10,000 live and carrier frequency of 1 in 40 to 1 in 60.This disease is classified in 4 grades of severity depending upon the age of onset and motor function achieved as SMA I, II, III and IV. It is caused by homozygous mutation of the survival motor neuron I gene (SMN I) which is a diagnostic test. ${ }^{8}$

\section{CLINICAL CLASSIFICATION OF SMA:}

\begin{tabular}{|l|c|}
\hline \multicolumn{1}{|c|}{ Types } & Onset of age \\
\hline Type I (Werding - Hoffmann disease) & $0-6$ months \\
\hline Type II (Intermediate) & $7-18$ months \\
\hline Type III (mild Cugelburg -Welander disease) & $>18$ months \\
\hline Type IV (adult type) & $2^{\text {nd }}-3^{\text {rd }}$ decade \\
\hline
\end{tabular}

Infants with SMA usually come for gastrotomy procedure, osteotomy, muscle biopsies, tracheostomy etc. This infant fits into type I SMA which is the most severe and common type of the disease. And accounts for about $50 \%$ of the patients diagnosed with SMA. 
This infant presented with hypotonia, no head control, symmetrical flaccid paralysis absent DTR and repeated chest infection with feeding difficulties.

Anaesthetic challenges included difficult intubation, post-operative respiratory support, increased sensitivity to the Non-Depolarizing Muscle Relaxants, hyperkalemia with succinyl choline and more sensitivity to the opioids. ${ }^{4}$ Though both general and regional anaesthesia have been e tried in these groups of patients, none of them are absolutely contraindicated. Graham and Athiraman 4 have conducted a retrospective study 25 cases of SMA and concluded that peri-operative care can be provided for children with SMA effectively under TIVA or inhaled anaesthetic agents along with the judicious use of opioids to improve patient comfort without increased morbidity.

There are also reports of cases where muscle relaxants are used in LSCS in type 3 SMA with uneventful recovery and no prolonged muscle weakness. ${ }^{5}$ Stuke and stuth first reported the use of NDMR in 18 months old child with SMA mild type $1 .^{6}$ They suggested that the pronounced difference in recovery times of diaphragm and limb muscle in the patient was most likely due to the muscle group in the primary disease. In the present we preferred maintenance of anaesthesia with intravenous agents because of the above said anaesthetic considerations.

This will avoid use of respiratory depressant agents because of the concern of alteration in respiratory drive in the context of base line restrictive and neuromuscular respiratory insufficiency. ${ }^{4}$

Regional technique may be preferred alone or as an adjuvant for the concern about the ventilatory dependence following general anaesthesia. ${ }^{9}$ Postoperative pain management can be done by only acetaminophen and local infiltration. ${ }^{9}$ Thus perioperative care can be tailored in accordance with functional status of the care.

CONCLUSION: SMA is an autosomal recessive disease which is associated with anaesthetic risks like difficult airway, hyperkalaemia, malignant hyperthermia, and post op ventilator support with rare circulatory complication. Post op respiratory complications are more in SMA because of the inability to swallow, cough, protect airways and maintain adequate gas exchange. While choosing anaesthetic techniques and agents, the strategy should be to minimize alterations in the chest wall dynamics caused by residual effect of muscle relaxants or high level of neuroaxial blockade and to avoid excessive depression of central respiratory drive. ${ }^{4}$

The present report recommends that TIVA technique is more beneficial for PEG insertion without any complications and provides smooth recovery in type 1 SMA infants.

\section{REFERENCES:}

1. D'Amico A, Mercuri E, Bertini E. Spinal muscular atrophy. Orphan et J Rare Dis 2011; 6: 71.

2. Iannaccone ST. Modern Management of Spinal Muscular Atrophy. Journal of Child Neurology 2007; 22(8):974-8.

3. Islander G. Anaesthesia and spinal muscle atrophy, Paed Anesth 2013 Sep; 23 (9): 804-16.

4. Graham RJ, Athiram RG, Lubach A. E, Skanthana NF. Anaesthesia peri-operative medical management of children with spinal muscular Atrophy. Paed Anesth 2009; 19: 1054-63.

5. Case reports on anaesthesiology Vol-2011 Article ID 743587.

6. Stalk AG, Estuth EA. Use of rapacuroium in a child with SMA. Paed Anesth 2001; 11: 725-8.

7. Cote CJ, Lerman J, Todres ID. A practice of Anesthesia for Infants and Children. (4th Ed) (2009) p. 498-499. 


\section{CASE REPORT}

8. Wilton NT. Spinal muscular atrophy; " the challenges of doing the right thing". Paed Anesth 2009; 19: 1041-7.

9. Yuan. $\mathrm{N}$ et al. Laparoscopic Nissen fundoplication during gastrostomy tube placement and noninvasive ventilation may improve survival in type I severe type II spinal muscular atrophy. J Child Neurol 2007; 22: 727-31.

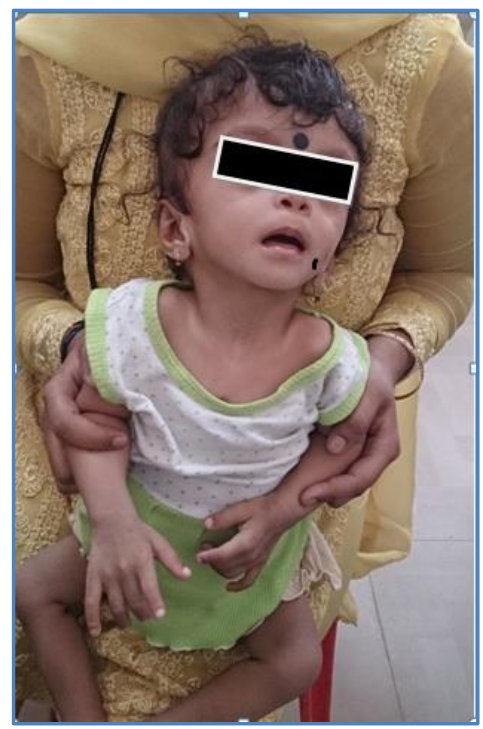

Figure 1

\section{AUTHORS:}

1. Chandrakala K. R.

2. Bhagya D. V.

3. Chandrika Y. R.

4. Anuradha G.

5. Madhavi N.

\section{PARTICULARS OF CONTRIBUTORS:}

1. Assistant Professor, Department of Anaesthesiology, Indira Gandhi Institute of Child Health, Bangalore.

2. Fellowship Student, Department of Paediatric Anaesthesiology, Indira Gandhi Institute of Child Health, Bangalore.

3. Professor and HOD, Department of Paediatric Anaesthesiology, Indira Gandhi Institute of Child Health, Bangalore.

4. Assistant Professor, Department of Paediatric Anaesthesiology, Indira Gandhi Institute of Child Health, Bangalore.
5. Associate Professor, Department of Paediatric Anaesthesiology, Indira Gandhi Institute of Child Health, Bangalore.

\section{NAME ADDRESS EMAIL ID OF THE} CORRESPONDING AUTHOR:

Dr. Chandrakala K. R,

Shrinidhi, 805/I,

Kanakapura Road, $15^{\text {th }}$ Cross, Jayanagar, $7^{\text {th }}$ Block, West Bangalore-560070.

Email: chandrakalakr@yahoo.com

Date of Submission: 03/07/2014.

Date of Peer Review: 04/07/2014.

Date of Acceptance: 12/07/2014.

Date of Publishing: 19/07/2014. 